\title{
THERMOACOUSTIC REFRIGERATOR SYSTEM PERFORMANCE USING THE PVC (POLYVINYL CHLORIDE) STACK BY POWER INPUT VARIATION
}

\author{
Indah Kharismawati \\ Institut Keguruan dan Ilmu Pendidikan Persatuan Guru Republik Indonesia Jember \\ Jl. Jawa No. 10 Jember 68121
}

Recieved: 03 ${ }^{\text {th }}$ March 2017; Revised: $27^{\text {th }}$ April 2017; Accepted: $30^{\text {th }}$ April 2017

\begin{abstract}
Thermoacoustic refrigerator is an innovative alternative and did not use substances that had a negative impact on the environment such as freon, but using air as the working substance. The materials used the refrigerator was easily obtained and the components construction was simple so that made this refrigerator was cheap, easy to make and easy to maintain. Stack was used in the thermoacustic refrigerator system used PVC (Polyvinyl chloride) which is parallel cylindrical shape and diameter $(1.50 \pm 0.05) \mathrm{mm}$ and length of $8 \mathrm{~cm}$. Variations of loudspeaker input power that used were 20 watt, 30 watt, 40 watt, 50 watt and 60 watt. Variations of the input power that used to determine the effect of loudspeaker input power to decreasing temperature in the operating of the thermoacoustic refrigerator system using PVC stack. From the result, loudspeaker input power influenced on the decreasing temperature that was $6.0^{\circ} \mathrm{C}$ for 20 watts, $6.7{ }^{\circ} \mathrm{C}$ for 30 watts, $7.2{ }^{\circ} \mathrm{C}$ for 40 watts, $8.0{ }^{\circ} \mathrm{C}$ for 50 watts and $9.0^{\circ} \mathrm{C}$ for 60 watts. From these results indicated optimum decreasing temperature depended on the amount of loudspeaker power that was directly proportional to the decreasing temperature obtained.
\end{abstract}

Keywords: Thermoacoustic Refrigerator, Stack PVC, Power Input

\section{Introduction}

Thermoacoustic is a study of the interaction between thermal and sound, namely the conversion of thermal energy into sound energy which is called the "Thermoacoustic effect". ${ }^{1}$

Basically, thermoacoustic refrigeration is the phenomenon of energy transfer from cold tohot which is produced by generating the acoustic waves field around the periphery of solid objects taken from a stack made of objects parallel piles to the standing wave devices $^{2}$ within the meaning easier tounderstand, a sound wave is able to cause temperature difference because of air through small canals in propagation.

Thermoacoustic refrigerant does not use substances which have negative effect on theenvironment such as CFCs (Chlorofluorocarbons), but uses gas (helium, xenon, air) as theworking substance which does not cause damage to the ozone layer and does not cause green house effect.

Research in the thermoacoustic field both thermoacoustic refrigeration or thermoacoustic heat engine has been done, especially in terms of shape, design, size and materials that used in the manufacture of resonator tube and stack. The researches include the following: Stainlessteel Aplication with an outer diameter $18.5 \mathrm{~mm}$ the variation in the length of 4 to $9 \mathrm{~m}$ obtained the optimum length of $8 \mathrm{~m}$ and the temperature obtained is $88.6 \mathrm{~K} .{ }^{4}$ Mean while, in a research states that the terms of a resonator tube should have the following elements: solid, light and strong enough. The aplication of metal cylinder with diameter ratio in then arrowing of resonator tube 0,54 can reduce energy loss 0.2 watt. $^{5}$ Thermoacoustic refrigerant research uses resonator tube of PVC material with diameter 
$60 \mathrm{~mm}$ capable of producing temperature in cold tendon reaches Tcold $=18.5^{\circ} \mathrm{C} .{ }^{6}$

Stack is the most important part in thermoacoustic device, the function is retaining thermal that prevents thermal contact between the left and right reservoir of the stack, as well as a thermal exchanger used to move thermal from one reservoir to another reservoir. Stack is composed of surfaces parallel set or random to the different axis tube resonances in the region of the temperature gradient along the tube. The optimum layout of the stack in the model standing wave resonator tube is surrounded regions that the distance $\lambda / 20$ from the intersection node or the tube resonator cover.Stack should have low thermal conductivity material so that the temperature is trapped in the stack does not pull back. In this case the pumping thermal in the stack can run effectively and the temperature in the stack can be stabilized. The space between the stack layers also take effect to the thermoacoustic device performance. If the space between the layers are too large will cause the gas can not transfer thermal effectively to and from the walls of the stack and vice versa if the space between the layers of the stack are too narrow will impede gas to oscillate. $^{5}$

Figure 1.shows the cycle of refrigerator process or thermal pumping of thermoacoustic. Before thermoacoustic device is operated, the temperature on both reservoirs are same. When thermoacoustic device starts operating, the oscillation of sound waves cause the gas packages in the stack move from cold reservoir to the hot reservoir (to the left). Adiabatic process occurs at step 1 (from 1 to 2) when the gas packages volume are compressed because of higher pressures in the near hot reservoir, so the temperature rises. As a result, gas package to be hotter than the stack wall nearby so the package gas releases thermal to the walls of the stack and the gas package volume shrinks, this process is an isothermal process that occurs in step 2 (from 2 to 3 ). Step 3 package gas moves back to the right because the right side has lower pressure (from 3 to 4), it is adiabatic process that is when the streched package volume gas (adiabatic) due to a lower pressure near the cold reservoir, so the temperature drops. Step 4 package of gas to be colder than the walls of the stack nearby, so the package gas absorbs thermal from the stack wall and fluffy (from 4 to 1 ). This cycle recurs then there is the temperature difference is large enough at the ends of the stack. Stack end wall space that is added by thermal hot reservoir while the end wall space that is taken the thermal into the cold reservoir. This process will stop when the sound source is turned off. Gas package is referred to in this discussion is a package of gas that are closest to the stack. ${ }^{7}$
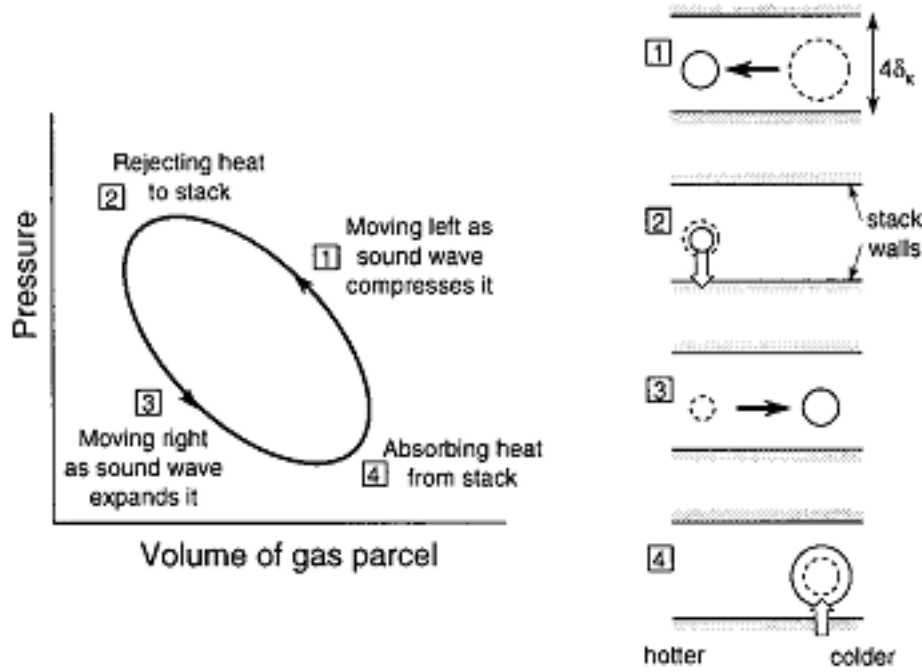

Figure 1.(a) Diagram $P-V$, (b) Diagram of thermoacustic refrigerant cycle ${ }^{7}$ 
Thermal penetration depth is a Must note, thermal penetration depth $\left(\delta_{k}\right)$ is the distance of thermal diffusion through the gas in the interval $\mathrm{t}=1 / \pi f$ with $f$ is the frequency of sound waves. Thermal penetration depth depends on the gas thermal conductivity $(k)$ and the gas $\operatorname{density}(\rho)$ as well, the thermal capacity per unit of the gas mass $\left(\mathrm{c}_{p}\right)$ as ${ }^{8}$ :

$$
\delta_{\kappa}=\sqrt{\frac{\kappa}{\pi \rho c_{p} f}}
$$

if the air as a gas at atmosphere pressure (1 atm) and room temperature is 27 degrees Celsius, with an air conductivity $(\kappa=$ $0,02638 \mathrm{~W} / \mathrm{m} . \mathrm{K})$, air density $(\rho=1,16$ $\mathrm{kg} / \mathrm{m}^{3}$ ), and the specific thermal per unit gass mass $\left(c_{p}=1007 \mathrm{~J} / \mathrm{kg} . \mathrm{K}\right)$, the thermal penetration depth as

$$
\delta_{\kappa}=0,25 \frac{1}{\sqrt{f}}
$$

so $r_{h}<<\delta_{k}$ the frequency of the sound waves $(f)$ must be lowest. It allows the thermal transfer in the cycle nearing isothermal.

This study uses a parallel cylinder stack diameter $(1.50 \pm 0.05) \mathrm{mm}$ and a length of 8 $\mathrm{cm}$. Stack material that used is of the cable sheathing is made of PVC (polyvinyl chloride). It was chosen because, stack used insulator material having a thermal conductivity low enough, besides that the PVC material is solid form so it is not easy to move and change the shape, and also is available in a cylinder so that it fits as a stack.

In this study the variation of the loudspeaker input power that is used is 20 watt, 30 watt, 40 watt, 50 watt and 60 watt. Those variations are used to determine the effect of loudspeaker input power to the decreasing temperature in the operating of thermoacoustic refrigerator system using PVC stack.

\section{Methods}

\section{Resonator Tube}

Resonator tubes is made of PVC pipe with length of $87 \mathrm{~cm}$ and a diameter in $(5.25 \pm$ $0.05) \mathrm{cm}$. Resonator tube consists of three parts (Figure 2), namely;

1. The part that is directly connected with a loudspeaker which has a length of 66 $\mathrm{cm}$.

2. The part that contains the stack with a length of $8 \mathrm{~cm}$.

3. Cover tubes length of $13 \mathrm{~cm}$.

\section{Stack PVC (Polyvinyl Chloride)}

Stack PVC (polyvinyl chloride) is parallel cylinder is made from a single wire cable sheathing diameter $(1.50 \pm 0.05) \mathrm{mm}$ that has already available form the cylinder so easy to use as stack. Cable sheathing that has already removed the copper wire is cut each $8 \mathrm{~cm}$ and placed parallel to the PVC pipe with diameter of 5.25 same as resonator tube, until met to form the diameter.

\section{temperature sensor}

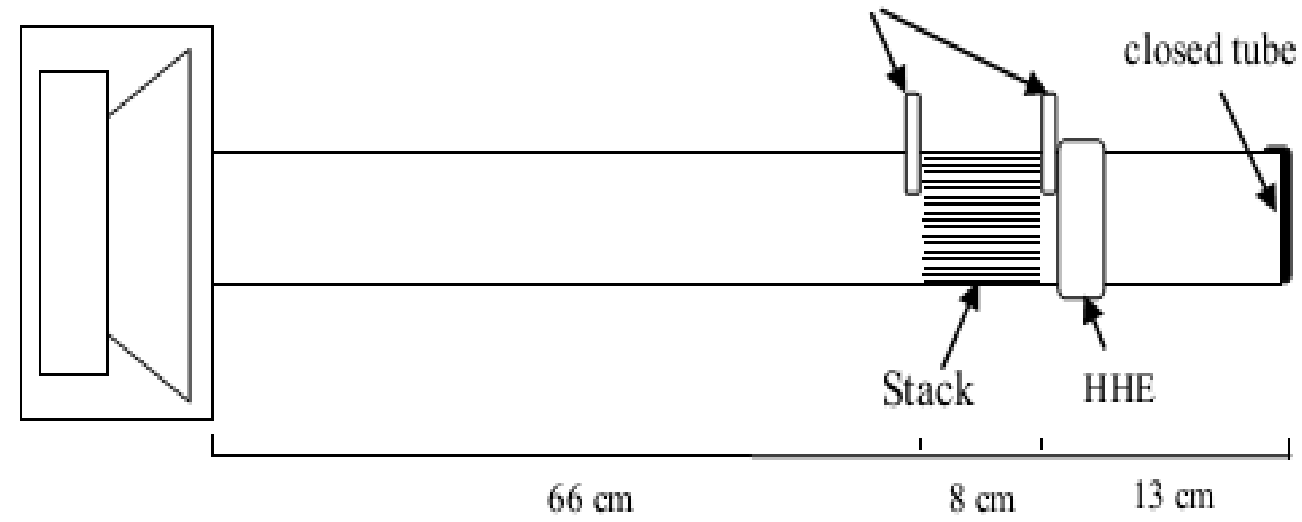

Figure 2. Resonator Tube 


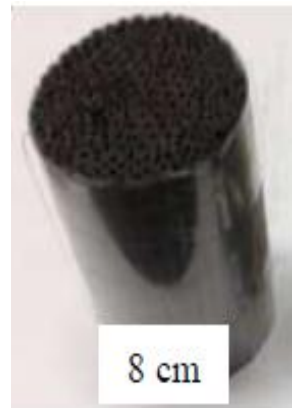

Figure 3. Stack PVC (polyvinyl chlorida) from single wire cable sheathing diameter $(1.50 \pm 0.05) \mathrm{mm}$

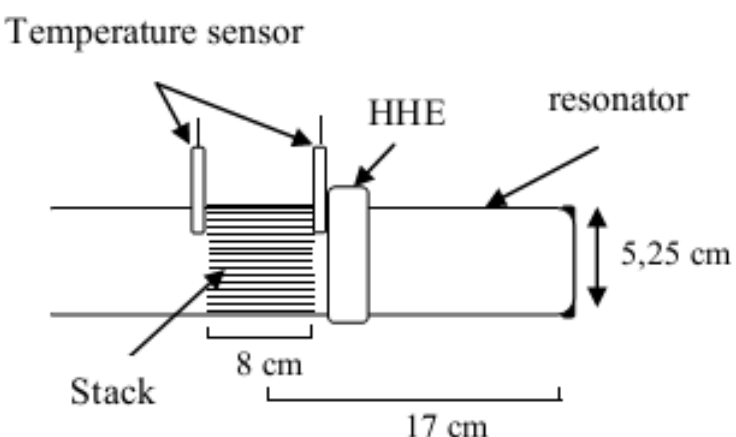

Figure 4. Stackis placed $\lambda / 20$ from the closed end of the resonator tube.

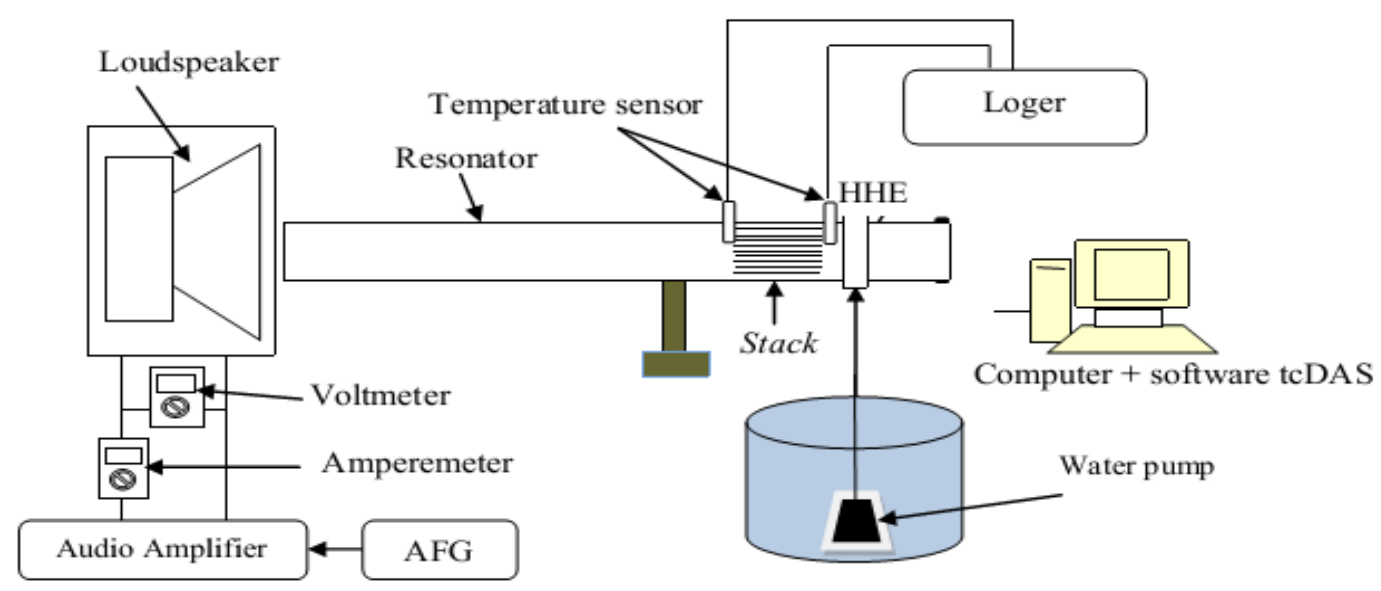

Figure 5. Schematic of thermoacoustic device series

\section{Assembly and Operating Equipment}

Stack up to $8 \mathrm{~cm}$ with diameter $5.25 \mathrm{~cm}$ is placed $17 \mathrm{~cm}$ from the closed end of the resonator tube, measured from the midpoint of the stack length (Figure4).

AFG is set on the resonant frequency. TcDAS software in the computer is started, on the computer screen will be seen hot and cold temperature reservoir. Before the audio amplifier carries the signal to vibrate the loudspeaker, both of the reservoirs must be at the same temperature tolerance (maximum difference) of $0.2^{\circ} \mathrm{C}$. Resonator tube must be closed without a hole. Making sure about that, the end of the pipe near the hot reservoir must be closed.

Complete series schematic entire thermoacustic system showed in Figure 5.

Once the thermoacoustic device is operated immediately available decreasing temperature in the cold reservoir and the increasing temperature in the hot reservoir. However after a few minutes the temperature in the reservoir is no longer decreasing temperature even temperature rises due to the back flow of thermal from the hot reservoir. It indicates the temperature on the hot reservoir has already saturated. To reduce the saturation, thermal in the hot reservoir needs to be discarded into the environment by flowing water in the hot heat exchanger (HHE). It is effected the temperature on hot reservoir is down, so that the process of thermal pumping from the cold reservoir to the hot reservoir is not disturbed by the back flow of thermal from the hot reservoir to the cold reservoir so that the temperature on the cold reservoir will be down. 


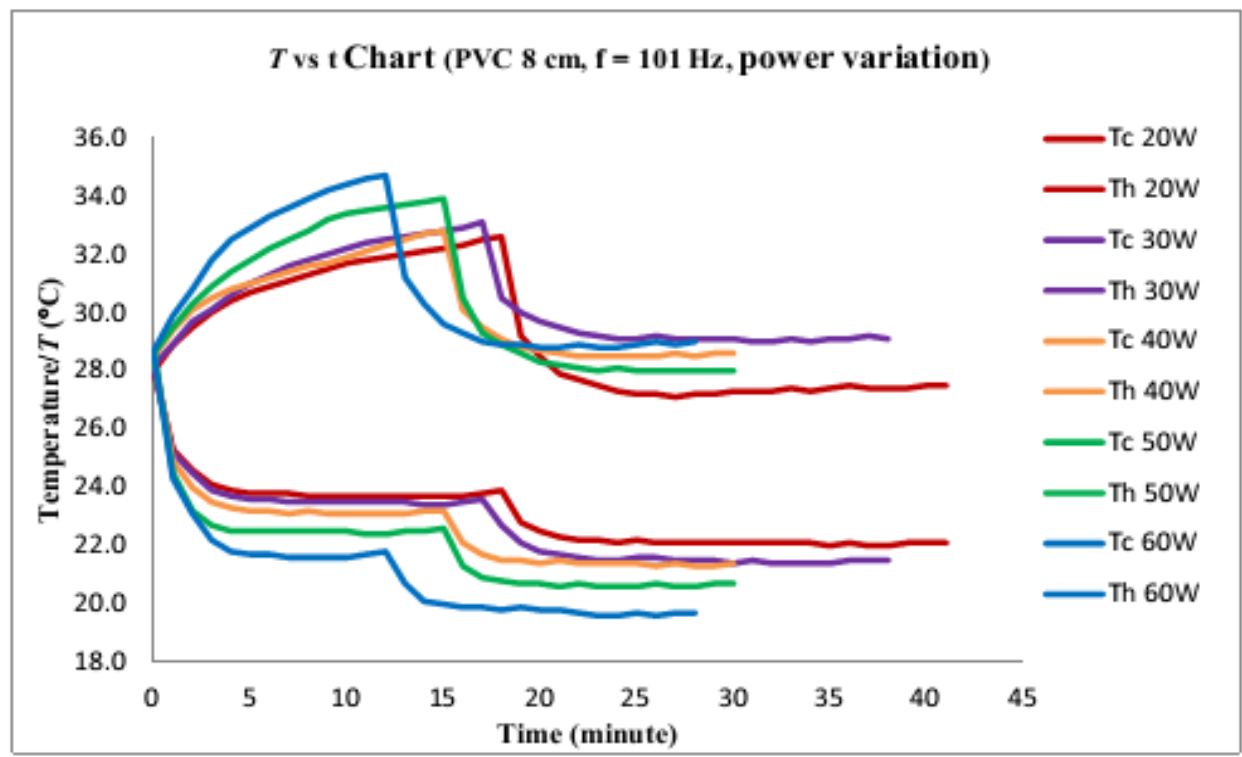

Figure 6. Variation of the loudspeaker input power to change the hot temperatures $\left(T_{\mathrm{h}}\right)$, cold temperature $\left(T_{\mathrm{c}}\right)$

\section{Result and Discussion}

Observation of the input power variation of sound source to the decreasing temperature has done on the best stack material that has been already obtained from previous research that is PVC cable sheathing materials length of $8 \mathrm{~cm}$, and using the optimum resonance frequency that has already observed on the material that is $(101.0 \pm 0,5) \mathrm{Hz}$. The experimental results transformation temperature on both of reservoir with input power variation of the sound source is showed in Figure 6.

Figure 6. shows that the optimum decreasing temperature depends on how much the loudspeaker power. From these results, the amount of the loudspeaker power used on the stack PVC cable sheathing materials have the greatest decreasing temperature or optimum up to $19.6{ }^{\circ} \mathrm{C}$ or $9.0{ }^{\circ} \mathrm{C}$ relative to the initial temperature, which occurs in the greatest input power that is 60 watt. In general it can be said that the greater power that used it will be faster the achievement of optimum decreasing temperature, and conversely the smaller power that used it will be slower the achievement of optimum decreasing temperature.

Here is a bar chart that shows decreasing temperature before the end after HHE water flowed toward the input power variation on the stack PVC cable sheathing material showed in Figure 7.

Table 1. Shows time taken before HHE flowed water to reach the optimum decreasing temperature to power variation

\begin{tabular}{ccc}
\hline $\begin{array}{c}\text { Power } \\
\text { (watt) }\end{array}$ & $\begin{array}{c}t \\
\text { before HHEflowed water } \\
\text { (minutes) }\end{array}$ & $\begin{array}{c}\Delta T_{c} \text { before HHEflowed } \\
\text { water }\left({ }^{\circ} \mathrm{C}\right)\end{array}$ \\
\hline 20 & 16 & 4,3 \\
30 & 15 & 4,7 \\
40 & 13 & 5,4 \\
50 & 12 & 6,2 \\
60 & 10 & 7,0
\end{tabular}




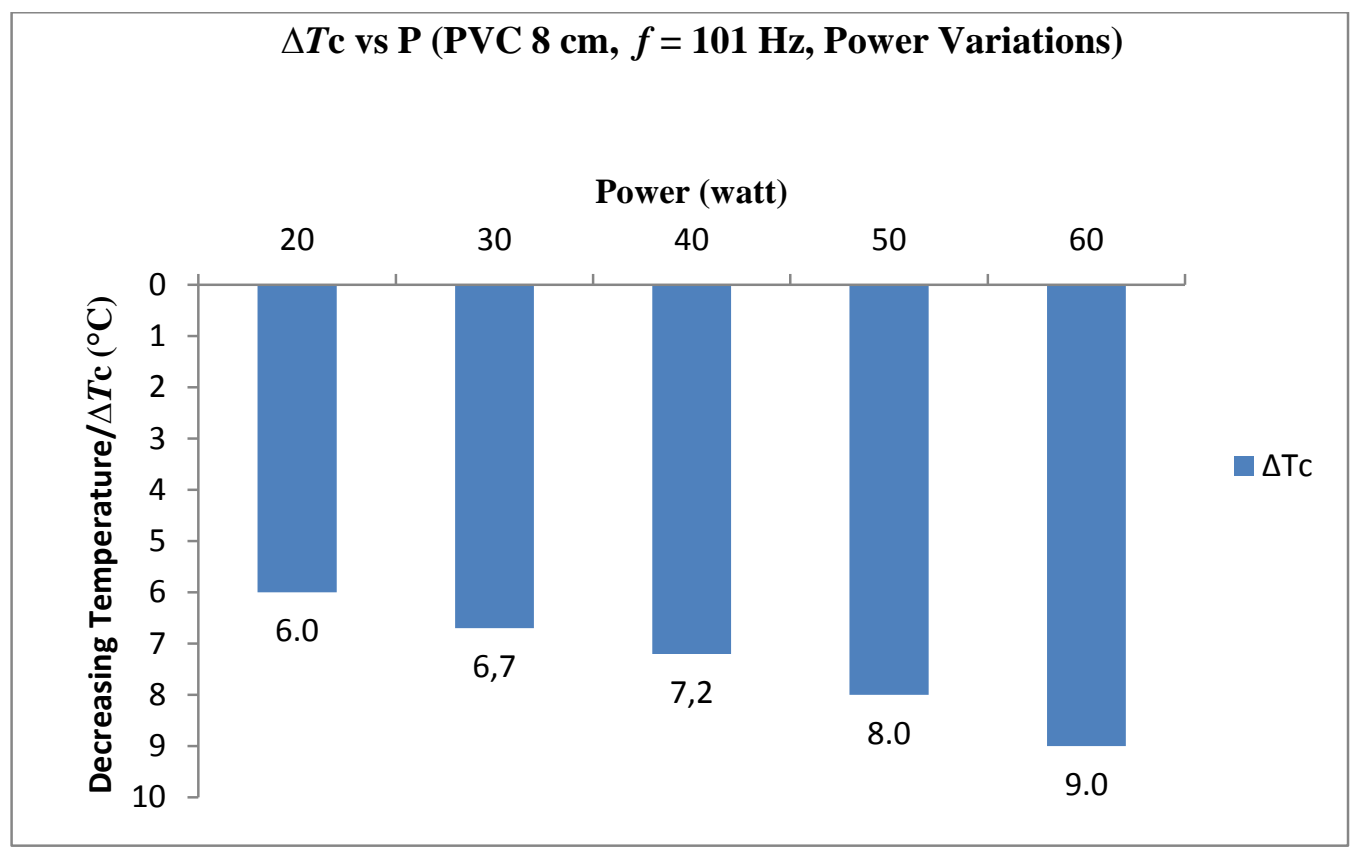

Gambar 7. Variation ofthe loudspeakerinput power toward decreasing temperature

Figure 7.shows optimum decreasing temperature depends on the amount of the loudspeaker power. Based on the picture shows clearly that the input power of the sound source takes effect on decreasing temperature namely $6.0^{\circ} \mathrm{C}$ to 20 watt, $6.7^{\circ} \mathrm{C}$ to 30 watt, $7.2{ }^{\circ} \mathrm{C}$ to 40 watt, $8.0{ }^{\circ} \mathrm{C}$ to 50 watt and $9.0{ }^{\circ} \mathrm{C}$ to the power of 60 watt. From the results can be concluded that the power of the sound source is directly proportional to the resulting of decreasing temperature. In other words, if the power used on the loudspeaker is bigger then the decreasing temperature that obtained is relatively greater, and vice versa if the power used is lower then the decreasing temperature that obtained is relatively smaller.

\section{Conclusion}

Thermoacustic refrigerator system performance depended on how much the loudspeaker power. The amount of the loudspeaker power that used on PVC stack had the optimum decreasing temperature that was obtained, it reached temperature $19,6{ }^{\circ} \mathrm{C}$ or $9.0{ }^{\circ} \mathrm{C}$ relative to the initial temperature, which occured in the largest input power that was 60 watt and input frekuence was $101 \mathrm{~Hz}$.

The input power of the sound source is directly proportional to the result of the decreasing temperature that obtained, in other words the increasing of input power obtains the greater decreasing temperature and also the faster optimum decreasing temperature in the thermoacousticrefrigerant system

\section{Acknowledgment}

The author want to say thanks to Thermoacoustic FMIPA UGM research group, IKIP PGRI Jember for supporting in this publication.

\section{References}

1. Jaworski AJ, Mao X. Development of thermoacoustic devices for power generation and refrigeration. Journal Power and Energy [Internet]. 2014 July [cited 2017 Feb 28];227(7):762-782. Availablefrom:http://journals.sagepub.co m/doi/pdf/10.1177/0957650913493622

2. Marx D, Mao X, Jaworski AJ. Acoustic coupling between the loudspeaker and the resonator in a standing-wave thermoacoustic device.Applied Acoustics. 2006:67(5):402-419. doi:10.1016/j.apacoust.2005.08.001

3. Panara KS, Patel AM, Patel NS, Patel JD. Thermoacoustic Refrigeration System 
Setup. International Journal of Mechanical Engineering and Technology (IJMET) [Internet]. 2015 Nov [cited 2017 Feb 24];6(11):1-15. Available from:http://www.iaeme.com/MasterAdmi n/UploadFolder/IJMET_06_11_001/IJME T_06_11_001.pdf

4. Tang K, Chen GB, Jin T, Bao R, Kong B, Qiu LM. Influence of resonance tube length on performance of thermoacousically driven pulse tube refrigerator. Elsevier International Journal of Cryogenics. 2005:45(3):185-191. doi:10.1016/j.cryogenics.2004.10.00

5. Tijani MEH, Zeegers JCH, De Waele ATAM. Design of Thermoacoustic Refrigerators. Elsevier International Journal of Cryogenics. 2002:42(1):49-57. doi:10.1016/S0011-2275(01)00179-5
6. Ghazali NM, Anwar M, Settar NH. Thermoacoustic Cooling with No Refrigerant. International Journal of Technology [Internet]. 2011 [cited 2017 Feb 25]:2(3):234-241. Available from: http://www.ijtech.eng.ui.ac.id/index.php/j ournal/article/view/72

7. Russell DA, Weibull P. Tabletop Thermoacoacoustic Refrigerator for Demonstrations. American Journal of Physics. 2002:70(12):1231-1233. doi:10.1119/1.1485720

8. Nsofor EC, Celik S, Wang X. Experimental Study On the Heat Transfer at the Heat Exchanger of the Thermoacoustic Refrigerating System. 2007:27(14-15):2435-2442.

doi:10.1016/j.applthermaleng.2007.03.008 